\title{
The Evolution of Competitive Intelligence in China
}

\author{
Xinzhou Xie * and Xuehui Jin **
}

\author{
* School of Journalism and Communication, Peking University, Beijing, \\ 100871, China \\ * and ** Beijing Science and Technology Information Institute, Beijing, \\ China \\ ** Key Laboratory of Competitive Intelligence and Innovation Evaluation, \\ Beijing Academy of Science and Technology, Beijing, 100048, China
}

\section{xzxie@pku.edu.cn}

Received 20 May 2011; received in revised form 23 August 2011; accepted 21 December 2011

\begin{abstract}
Following landmark events during different historic periods, this paper divides the evolution of competitive intelligence (CI) in China into three main stages: CI introduction, CI localization and CI self-conscious marketization. Studies of CI developments are made based on five main aspects of the overall CI industry in China, including their historical skeleton of development, achievements and problems identified. Finally a forecast for the future development of CI in China is presented.
\end{abstract}

Keywords: Competitive Intelligence, China, Society of Competitive Intelligence in China

\section{Introduction}

Since 1978 China has been carrying out economic reforms and opening policies. As a result of the reforms Chinese enterprises gradually became the host of market competition and enlarged enterprises' right to autonomous management and decision making in a system of market competition. Meanwhile domestic markets in China gradually became part of the global market and enterprises faced a more intense competition. The changing of the role and the intensifying competition created new conditions for the coming and developing of CI in China. In the past institutes of science and technology information in China were mainly serving the government at a national and local level. In addition the institutes were serving science and technology organizations. From mid 1980s they began to think about their function as transferring along with general social environmental change and put forward the idea that institutes of science and technology information shall serve enterprises and develop new space for development. The introduction of CI catered to this wish. In a word, Chinese enterprises' CI consciousness and needs were awakened under a drive for new social conditions and related policies. 


\section{Analysis on the stages of CI evolution}

In China CI is mainly composed of five aspects: CI academic research, CI enterprise application, CI market, CI education and training, CI laws and professional ethics. The former three are the dominating parts of CI and control the evolutionary speed of CI (figure 1). Since significant events mainly take place in these three parts, we divided CI evolution into the following three stages: CI introduction, CI localization and CI marketization (figure 2).

There are two old sayings in China: "Racing each other is called competition, arguing face to face is called strife" and "know the enemy and know yourself, and you can fight a hundred battles with no danger of defeat". The sayings proves to what extent competition and intelligence has existed as concepts in China since ancient times. Modern CI aiming for the goal of serving enterprises and helping them create competitive advantages appeared from the 1980s and onwards. In 1980 Xianpei Yuan (Changhuo Bao et al., 2005) published the paper "The Difference and Correlation Between Intelligence and Information", published in No.1, of the Science and Technology Information Service. This was the first time intelligence appeared in Chinese academic journals. In 1987 Huaibao Liu (Qihao Liao, 2005) published "Discussion about Competitive Intelligence and its methods of information collection", in No. 2 of Knowledge of Library and Information Science. In the article CI received its own Chinese terminology, “竞争情报”. From the early 1980s to mid 1990s institutes of science and technology information in different places in China, especially at the Shanghai Institute began to introduce overseas CI theories and practices into China and advocated CI research and services. The first team engaging in CI research and promotion was formed. Their advocacy and activities were noticed by more and more Chinese information service

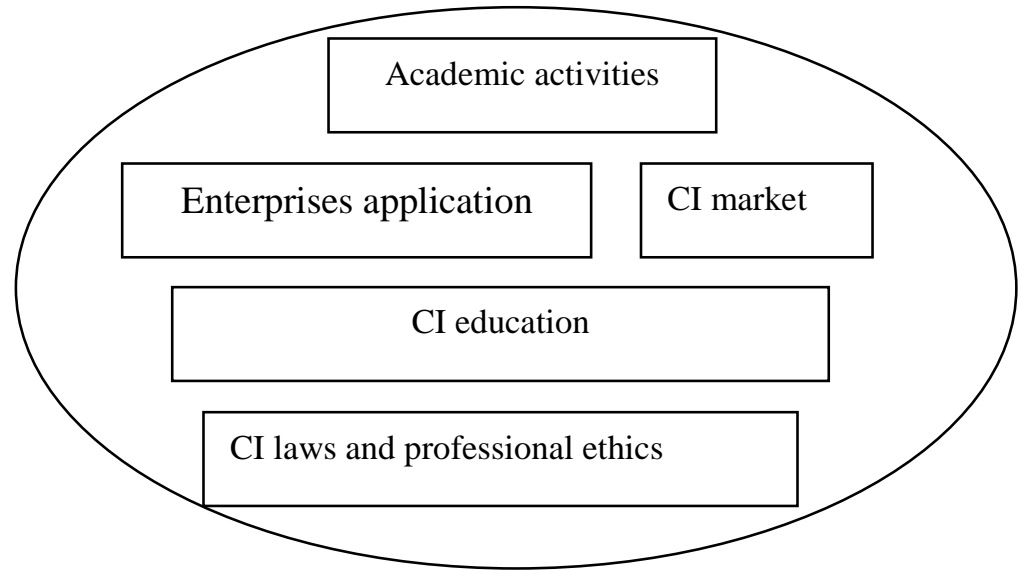

Figure 1: Five aspects of CI in China

Landmark events:

In 1980 Xianpei Yuan introduced the concept of CI in China. In 1987 CI got its Chinese terminology, “竞争 情报”。
Landmark events: In 1994 SCIC (Society of Competitive Intelligence) was founded.
Landmark events: In 2002 Baidu, a famous IT company at home and abroad, launched the first CI software, eCIS.

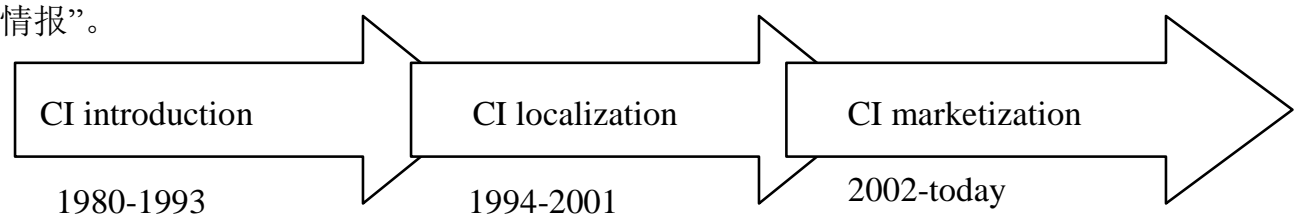

Figure 2: Stages of the evolution of CI in China 
organizations and academics. Thus, "Introduction" is an appropriate definition of this first stage on CI in China.

In 1994 the Society of Competitive Intelligence in China (SCIC) was founded, as a professional organization in China. It marked that CI now took an organized and more regularized road and greatly pushed the development of CI in the country. CI got a relatively rapid development in the aspects of academic research and CI education and obtained some achievements in CI localization studies. However, CI practices and the CI market were not yet very active.

At the end of the $20^{\text {th }}$ century a number of Chinese information companies such as Xuanxin CO. Ltd. and Menglong CO. Ltd. tried to develop CI software, but their products were only used by themselves and their customers as an accessory to CI consultation.

These attempts did not lead to any great response. Then Baidu, a famous IT company in China and abroad, launched the CI software product eCIS on the Chinese market. This caused a strong reaction to $\mathrm{CI}$ and had a major effects. Following Baidu, many companies entered the CI market. At the same time Autonomy, a British search giant, entered the Chinese CI market. Due to advertisements and promotions made by these companies, Chinese enterprises became greatly inspired. On this stage the CI market in China was gradually formed and enterprises' CI applications became more common than in the past. The CI academic circle was greatly encouraged by the flourish of the CI industry and saw various kinds of CI academic activities boom, including books, academic papers and CI conferences.

\section{Academic research}

\subsection{Academic papers}

CI was first introduced in Chinese academic circles in early and mid 1980s. Academics kept their enthusiasm and gained achievements especially after SCIC was founded in 1994. Before 1994 CI academic papers were rare and scattered. There were almost no CI papers in Chinese authoritative databases. Below we see statistics reflecting this new achievement, through two of the most authoritative databases, CNKI and VIP, using keywords retrieval and artificially eliminating irrelevant literature. From 1994 to 2009 academic papers on CI was 3019, keeping a steady annual rise, especially since the 2001 growth rate increased (figure 3).

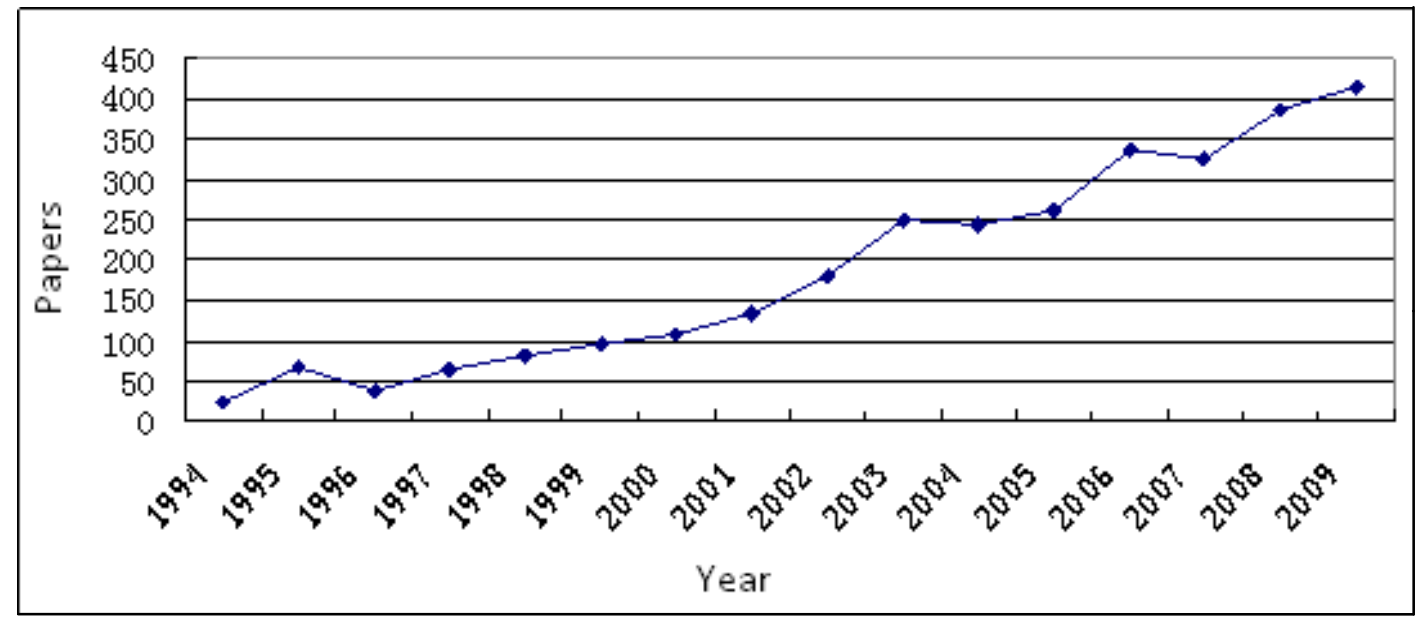

Figure 3: Annual distribution of CI papers

\subsection{Scholars}

CI Scholars were formed and developed as a result of the new active academic activities.
They brought new thoughts into the Chinese CI field through explorations, with academics 
such as Changhuo Bao (Changhuo Bao et al., 2006). He put forward the concept of Human Intelligence Network, and Xinzhou Xie et al. systematically analyzed the operation modes and mechanism of CIS (table1).

\begin{tabular}{|c|c|c|}
\hline Authors & $\begin{array}{l}\text { Works (books) and } \\
\text { papers }\end{array}$ & Research topics \\
\hline Bao Changhuo & 13 works, 47 papers & $\begin{array}{l}\text { human intelligence network, competitive intelligence } \\
\text { system }\end{array}$ \\
\hline Xie Xinzhou & 15 works, 19 papers & $\begin{array}{l}\text { human intelligence network, competitive intelligence } \\
\text { system, competitive technical intelligence, competitive } \\
\text { intelligence practices }\end{array}$ \\
\hline Chen Feng & 1 work, 34 papers & $\begin{array}{l}\text { national competitive intelligence, industry competitive } \\
\text { intelligence, strategy intelligence and competitive } \\
\text { intelligence }\end{array}$ \\
\hline Peng Jingli & 60 papers & $\begin{array}{l}\text { competitive intelligence practices, competitive technical } \\
\text { intelligence }\end{array}$ \\
\hline Wu Xiaowei & 31 papers & $\begin{array}{l}\text { human intelligence network, competitive intelligence } \\
\text { system and software }\end{array}$ \\
\hline Qin Tiehui & 25 papers & competitive intelligence and knowledge management \\
\hline Xu Fuyuan & 18 papers & $\begin{array}{l}\text { human intelligence network, competitive intelligence } \\
\text { system, competitive intelligence practices }\end{array}$ \\
\hline Li Yan & 17 papers & competitive technical intelligence \\
\hline Wang Yuefen & 13 papers & competitive intelligence system and software \\
\hline
\end{tabular}

\section{Table 1: CI scholars and main research directions}

Two of the most prominent Chinese CI researchers, professor Bao and Qin, recently retired. The Chinese CI community was then facing a new era where the representatives, Xinzhou Xie and Feng Chen et al., became the more active scholars within this field in China. At the same time representatives for the new CI generation, Yan $\mathrm{Li}$ and Xiaofei $\mathrm{Wu}$ et al. established themselves. Generally speaking, CI interest was still a bit weak and most scholars came from departments of Library and
Information Science or libraries at universities or institutes of information services in different provinces. The backgrounds of Chinese CI academics were narrow.

\subsection{Core achievements of academic localization research}

Six core topics were the focus of Chinese CI academics (table2).

\begin{tabular}{|c|c|c|c|}
\hline Core topic & Year & $\begin{array}{l}\text { Quantity } \\
\text { Publications }\end{array}$ & Main authors \\
\hline $\begin{array}{l}\text { Competitive intelligence system (CIS) and } \\
\text { software }\end{array}$ & $\begin{array}{l}\text { Early 1990s - } \\
2010\end{array}$ & 372 & $\begin{array}{l}\text { Changhuo Bao, Xinzhou } \\
\text { Xie, Fuyuan Xu. }\end{array}$ \\
\hline $\begin{array}{l}\text { Competitive intelligence and knowledge } \\
\text { management }\end{array}$ & $2000-2010$ & 130 & Tiehui Qin, Junping Qiu. \\
\hline Competitive technical intelligence & $2006-2010$ & 52 & Xinzhou Xie, Xiwen Liu \\
\hline Human intelligence network & 2003-2009 & 44 & $\begin{array}{l}\text { Changhuo Bao, Xinzhou } \\
\text { Xie. }\end{array}$ \\
\hline National competitive intelligence & $1989-2009$ & 32 & Qihao Liao, Gang Zhao. \\
\hline Industry competitive intelligence & $2006-2010$ & & Feng Chen \\
\hline
\end{tabular}


Table 2: CI core topics and researchers

\subsubsection{CIS and CI software}

Chinese researchers are now very interested in CIS and information technologies relating to CIS. They think CIS is the foundation of CI, its organizational guarantee, and the symbol of a mature and modern CI field (Changhuo Bao et al., 2004). From figure 4 we see that research on CIS has been carried out since the mid 1990s. In recent years Chinese academics have paid close attention to $\mathrm{CI}$.

At the beginning Chinese academics learned from foreign experts and introduced research
These findings were published in Research of Model and Operational Mechanism of Competitive Intelligence System and supported by NNSFC (the National Natural Science Foundation of China). The book "Enterprise Competitive Intelligence System” compiled by Prof. Bao and Prof. Xie was published in 2002. The books pins down thoughts on CI and CIS more systematically than before. This forms a theoretical foundation for CIS research and development in China.

In addition there appeared studies of CI software for information gathering, processing

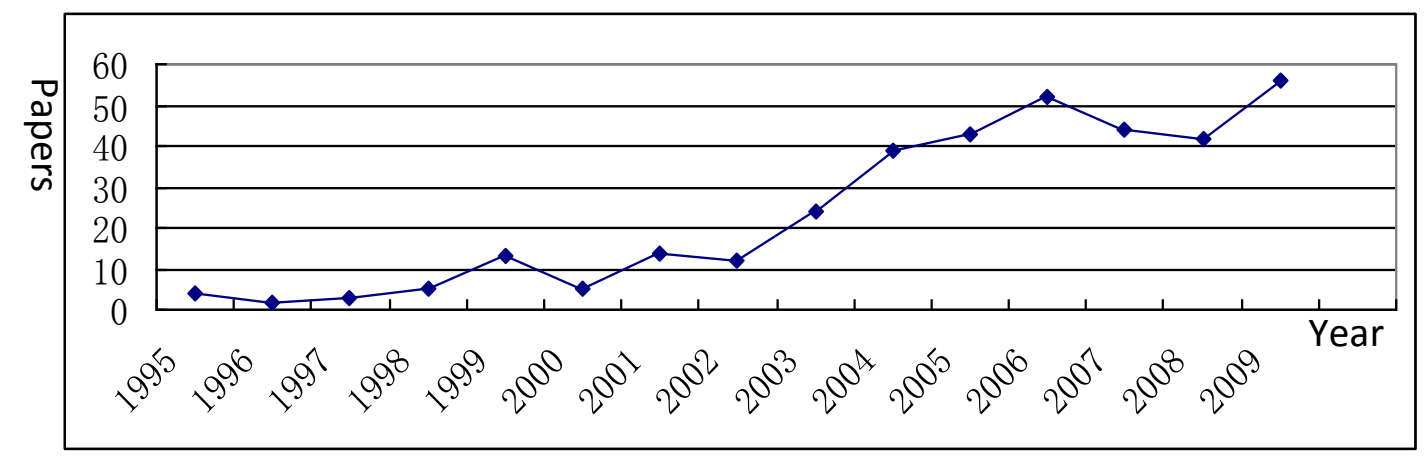

Figure 4: the curve of annual papers of CIS and CI software

on CIS. Then they tried their best to construct CIS theory based on Chinese enterprises' actual situations. In 1992 the first CIS program in China, "Competition Environment Monitoring for Shanghai automobile industry", tried to copy the work flow for CIS from American companies to Chinese enterprises. In 1999 Prof. Bao et al. systematically studied CIS' basic structure, model, functions and operational mechanism and constructed the basic framework of CIS integrating three CIS sub-networks (information sub-network, organization sub-network and human subnetwork), three information sub-systems (information gathering system, information analysis system and information service system), one centre (enterprise competitive intelligence centre) and six functions (environment monitoring, market warning, technologies tracking, opponents analysis, decision-making and information security). and analyzing. In early 1995 Xiangyu Tao (Xiangyu Tao et al., 1995) tried to construct a quick response system for competitive intelligence based on IT. In 2003 Keqiang Yin (Keqiang Yin, 2003) developed a milestone CI software. It includes five main modules around a CI cycle, CI need identification, secondhand information collection, primary information collection, CI analysis and CI services. In 2006 Wuhan University (Chao Sun et al., 2007) took responsibility for a program supported by NNSFC, "Research on Mechanism of Enterprise Competitive Intelligence Collection Based on Data Mining". It used advanced data mining techniques and developed an automatic classification system for enterprise competitive intelligence collection. At the beginning of the $21^{\text {st }}$ century CI software appeared on the Chinese market. The number of papers increased, but their findings were seldom put into practice. 


\subsubsection{CI and Knowledge Management (KM)}

In the information economy era $\mathrm{CI}$ and $\mathrm{KM}$ are playing a more important role in business management. Both have similarities in their research objects, methods and related technologies. That is the main reason why Prof. Guy D. Kolb (Li Liu, 2007), secretary-general of SCIP, started to list research on the relationship between CI and KM. Prof. Qiu and his students (Junping Qiu et al., 2005) discussed the correlation and difference between these two areas in 2000. Prof. Qin (Tiehui Qin et al., 2003) and Prof. Wang et al. (Yufen Wang, 2006) studied the problem how to realize the integration, including content and measures. From figure 4 we see the attention given to this problem. Before 2008 the interest increased and in 2008 it reached its summit, then to experience a straight decline. We think the reason is that new research on the topic is lingering for the management level and that demand has become saturated. The problem is waiting for an in-depth theoretical and technological breakthrough. Because both areas are important for Chinese enterprises, CI academics in China will continue to pay attention to this problem on CI and KM.

\subsubsection{Competitive technological intelligence (CTI)}

Before discussing this topic, we have to know something about the information service for science and technology in China. Since 1956 institutes of science and technology information has been founded in several major Chinese cities and an Information Service Network has been formed in these cities. They have also engaged in Public Service of Science and Technology Information. Its study object is the same as we call CTI, and in a certain sense the former is a predecessor of the later. Their fundamental difference lies in their objects. The former is serving governments at all levels, the latter enterprises. The former is public service, the later commercial service.

Since the 1980s the practice of CTI has appeared in some enterprises which focus on technology innovation, such as Haier (Wei Fang et al., 2008) and Bao Gang (Xiujuan Liang et al., 2009), but it hasn't caused much attention among Chinese scholars. Entering the early 21 st century the Chinese government stressed the importance of technology innovation for Chinese economic and national development. From that time, especially in 2006, many CI scholars have paid attention to CTI. Although the history of CTI research is short in China, the study on this topic is active and the level of research is relatively high. In 2000 Prof. Zhu and Prof. A. Proter (Yan Li et al., 2006) led the first CTI program in China, called "Study on Monitor and Analysis Technology of High Technology Based on Intelligent Knowledge-mining" (a NNSFC program). Following it came research such as technical innovation audit (Jin Chen et al., 2006), patent map (Ping L., 2005) and CTI methods framework (Xianneng Ke, 2008). Their research caused a renewed interest for CI. The CTI research boom increased in 2008 and 2010 with ITICTI (International Conference on Technological Innovation and Competitive Technical Intelligence) I and ITICTI II organized by Peking University and Beijing Academy of Science and Technology, attracting hundreds of people from universities, institutes of information service and companies from China and abroad. This produced hundreds of papers and gradually led to an

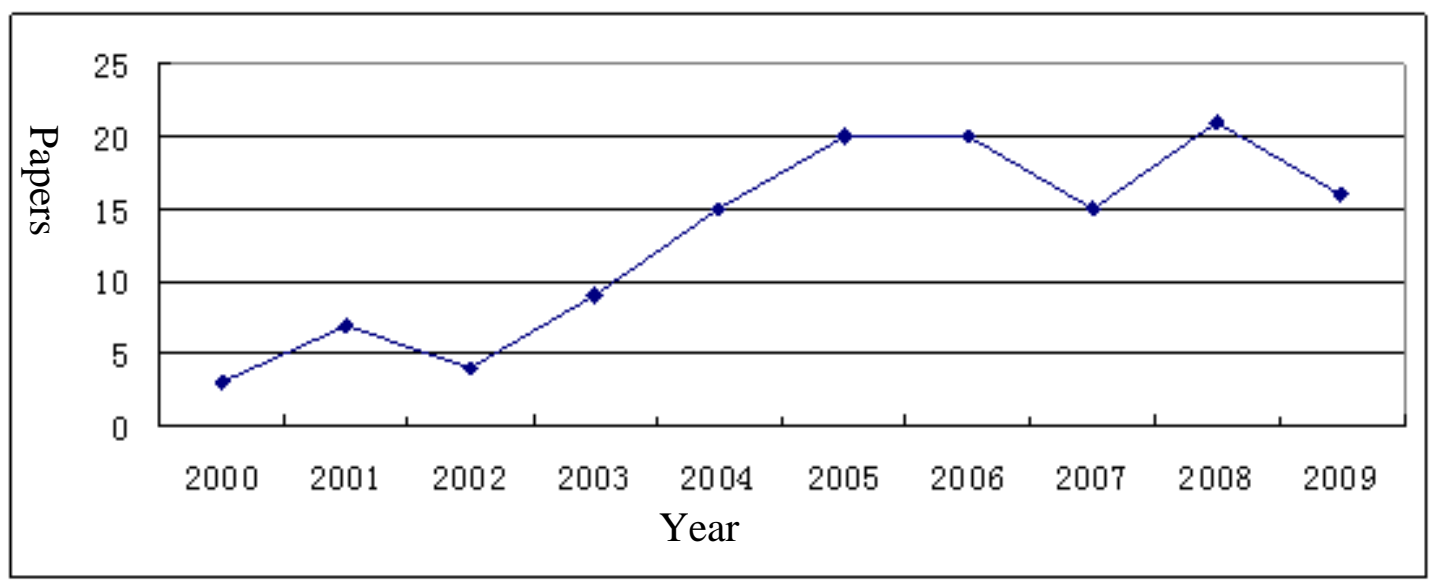

Figure 5: Curve of papers on the research of the relationship between CI and KM 
international reputation on $\mathrm{CI}$.

Within less than five years, academic papers on CTI published in magazines reached 52, and master thesis 3. Compared to other CI topics, the scope and speed of CTI research was striking.

The above discussions suggest that CTI will be an active research branch of CI scholarship in China.

\subsubsection{Human intelligence network}

In 1998 Bao Changhuo put forward the idea of human intelligence network for the first time in China, claiming that CIS is composed of three subsystems: intelligence network, organization network and human network. These three networks are equally important for CIS. In 2002 Prof. Bao et al. published two books about CI, "Competitive Intelligence Solutions Enterprise Competitive Intelligence System and Skills" and "Competitor Analysis". In 2005 Chuangye Yan, a Ph.D at Peking University, wrote his Ph.D dissertation entitled "Human Network in Competitive Intelligence Activities". It was an in-depth theoretical exploration and a construction of a practical model of human network in competitive intelligence activities. It was the first Ph.D dissertation to do research on human intelligence networks in China.

From 2003 to 2009, papers about the topic reached 44 . The overall trend of the research on human intelligence networks reached its peak in 2007. It then went down again. This indicates that academics still maintain an interest for the topic, but after completing basic research and exploration of human intelligence network, it is now in search of a breakthrough. Otherwise the topic may stop to be published in scientific journals in China.

\subsubsection{National Competitive Intelligence}

In early 1989 Qihao Liao and Zuozhi Zhang (Qihao Liao et al., 1989) wrote the paper,
“Anatomy of JETRO's Overseas Technological Intelligence Activities". It claimed that JETRO's overseas intelligence activities were a state version of competitive intelligence. The concept of state run competitive intelligence or national competitive intelligence then appeared in the literature. In 2002 Liao held a speech about this topic at the SCIC annual conference. From 2004 Gang Zhao (Gang Zhao, 2004) wrote several papers about this topic to advocate competitive intelligence at a national level. In 2008 Xiang Tao (Xiang Tao, 2008) compiled the book, "National Competitive Intelligence: What It Is, Why and How to do it". It presents a careful explanation about the definition, importance and operational modes of national competitive intelligence. Researchers then thought national competitive intelligence referred to the intelligence activities at the national level. From the definition above, there is an overlap between national competitive intelligence, generalized competitive intelligence, governmental competitive intelligence and industry competitive intelligence. A definition of the difference between these terms and others is suggested by Klaus Solberg Søilen (Klaus Solberg Søilen, 2005). But, because the above concepts are intercrossing and national competitive intelligence is difficult to grasp as a specialty most scholars in China have shown little interest in the topic. As a result we have seen papers about national competitive advantage decline to account for less than $0.01 \%$ of the total amount of CI papers (figure $6)$.

Research on national competitive intelligence is a useful attempt to enlarge the area of research and development of CI, but has so far not been successful.

\subsubsection{Industry competitive intelligence}

With rapid development of a global economic integration, industrial clusters have become an economic entity that governments actively cultivate. In 2008 the China Institute of Science and Technology Information set

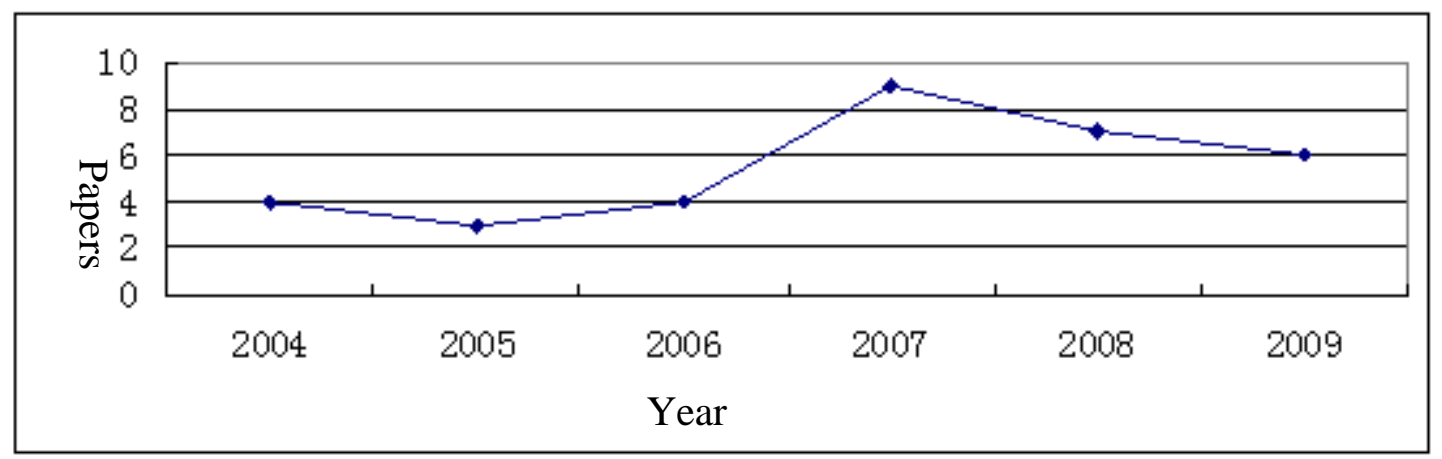


industry competitive intelligence as one of their research directions. For 3 years Feng Chen (Yanning Zheng et al., 2009) has been guiding colleagues and students in how to study its meaning, scope and characteristics. They divided CI into three levels from a macro- to a micro-scale, corporate CI, industrial and national. Their program was named "Basic Problems in Theories and Methods for industry - an empirical study" (a NNSFC program). It included all their thoughts on the topic.

After studying the background of industry CI, some of the literature turned towards the trend of thinking about enterprises not only as competing with each other but also as cooperating with each other. Unfortunately Chinese CI scholars in general are as of yet little concerned about this topic and research achievements in this area has been relatively weak. The number of academic papers on this problem is small and its research history short.

\section{The practice of CI in Chinese Enterprises}

Need for CI in enterprises is the basic drive of CI applications. The way of meeting CI needs generally includes two aspects: one selfsupplying, namely enterprises themselves carrying out $\mathrm{CI}$; the other buying $\mathrm{CI}$ services from external CI companies or organizations, namely buyers establishing business relationship with suppliers to develop the CI market. There are two kinds of driving forces of CI practices in China: one comes from the external, including CI research organizations, government at all levels and CI companies; the other is self-reflecting on CI activities.

\subsection{The combination of industry, officials and universities to accelerate CI applications}

\subsubsection{The background}

Before the 1980s, due to the fact that China was living in a planned economy, Chinese enterprises' awareness of CI was weak, and CI practices were in a state of "hibernation". In China universities and institutes of science and technology information encountered CI abroad for the first time. This caused great interest in $\mathrm{CI}$ in China. Since the influence of these companies were limited, they strived for governmental support and began to penetrate the field of CI for themselves to encourage enterprises to focus more on competition.

\subsubsection{Major events}

1. CI services specialized on public institutes of information services and universities: In 1992, as the first specialized CI service department directly working with enterprises in public institutes of information service in China was the "Market Research department" at Shanghai Institute of Science and Technology Information. Later the public institutes of information services and universities began to serve enterprises, with the "Enterprises Information Service Central" at the National Library, "Competitive Intelligence and Competitiveness Research Center" at Peking University, and "Key Library of Competitive Intelligence and Innovation Evaluation" at Beijing Academy of Science and Technology.

2. CI projects funded by local governments: In 1995 there was a first CI demonstration project supported by local government in China. The Beijing CI demonstration project was supported by the Beijing Municipal Science \& Technology Commission. It picked eight companies from eight industries to help them construct CIS. This opened up for a new model to promote CI practices through a combination of industry, officials and universities. After that, respectively in 2000, 2004 and 2005, Yunnan, Shenzhen and Hunan provinces successively started CI demonstration projects at the governmental level, involving hundreds of enterprises. These CI projects were organized to help local enterprises develop CI with the help of local institutes of science and technology information.

In addition SCIC made efforts to introduce CI to Chinese enterprises.

The organization attracted many enterprises to become members and inform them about CI. In 2006 SCIC established a Chinese Competitive Intelligence Consulting and Training Center. The organization established cooperative relationship with many enterprises such as Shanghai BAO Gang Group Corp., Qingdao Haier Group, and Beijing SHOUGNG Group.

\subsection{CI practices in enterprises}

\subsubsection{Background}

In the 1980s and 1990s, with the coming of new Chinese economic reforms and the opening up of the country's economy especially the transfer from planned economy to market economy - the Chinese government 


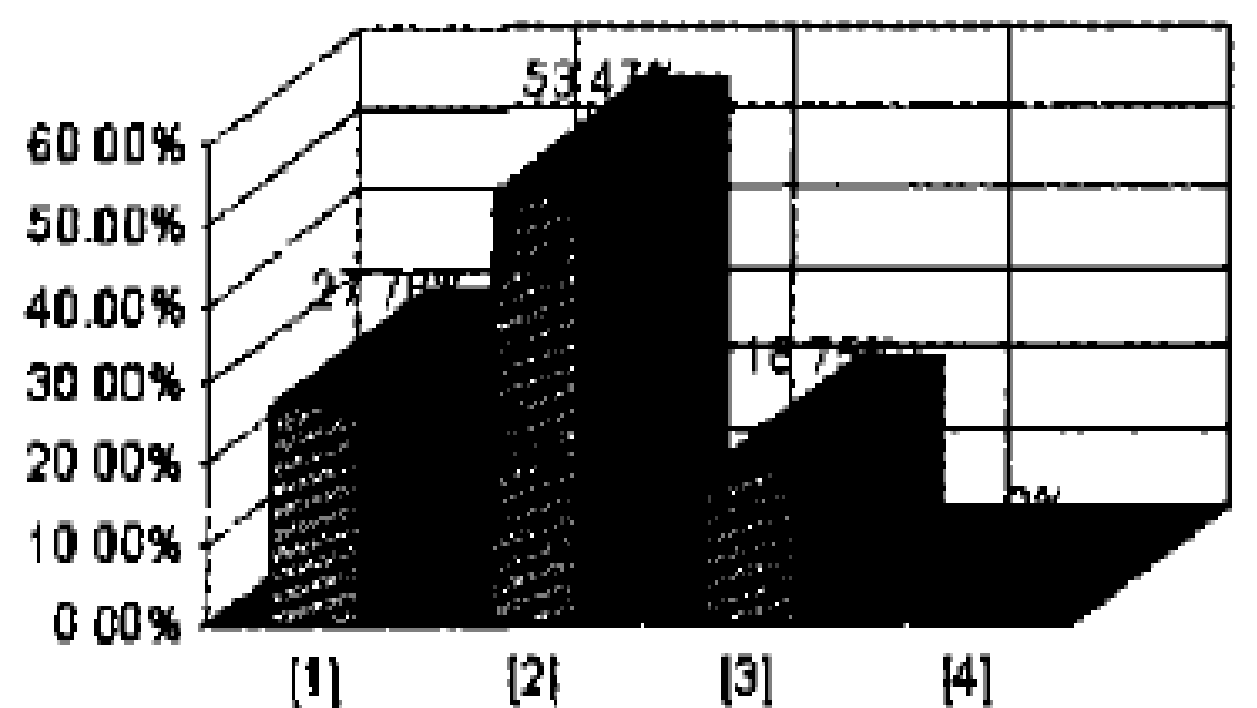

asked enterprises to take part in more market competition in China and abroad. Chinese enterprises had to depend more on themselves to survive and develop. This caused an increase in competition and meant they had to become more self-aware. This made Chinese enterprises become more focused on information collection and analysis for market intelligence and competitor intelligence. Many foreign companies such as IBM and SONY entered the Chinese market, bringing their own concepts of CI practices into China. At the same time academic organizations with their information institutions and the government encouraged Chinese enterprises to meet this challenge.

\subsubsection{CI practices in Chinese enterprises}

In 1999 Prof. Xie and his students systematically surveyed the situation of CI practices among Chinese enterprises. Based on their surveys, they divided the level of Chinese CI application into:

1. Having no CI workflow and network;

2. being in the process of constructing and forming;

3. having a regularized CI organization and network; and

4. having a CI workflow institutionalized and having world-wide CI networks.
The nationwide questionnaire survey done in 1999 shows the development level of CI in

Chinese enterprises (figure 7). From the figure we see that most companies, $53.47 \%$, found themselves at level [2]. $27.78 \%$ of the companies found themselves at level [1], $18.75 \%$ at level [3] and none at level [4]. This data suggests that by 1999 most Chinese enterprises were in the forming status. The level of CI was not high. With the rapid development of IT and the enhancement of enterprises" "informationalization", acquiring information was now easier than in the past. On the other hand the information explosion made enterprises decision-making more difficult.

After about ten years (2009), we visited and reinvestigated 93 companies with 87 valid questionnaires. The situations of industrial and regional distribution of $\mathrm{CI}$ implementation can be seen in figures 8-10. Due to limited time, the regional distribution of the companies involved in the survey was insufficient. The samples are mainly limited to Beijing and Shanghai. Beijing and Shanghai have the most companies among Chinese cities, and they are more developed economically than other Chinese cities so far. 


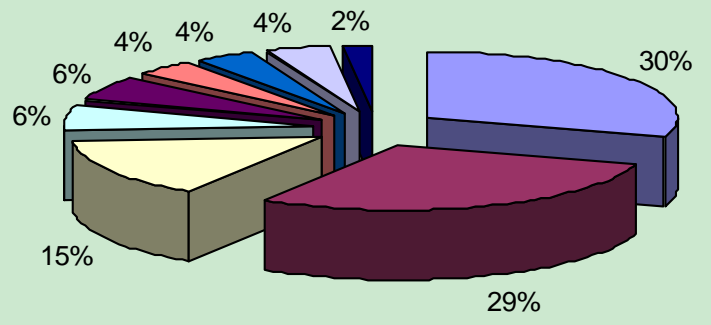

$\square$ information transmission, compute

service and software

$\square$ manufacturing

$\square$ commercial service

$\square$ petrochemical

$\square$ others

$\square$ service business

$\square$ transportation, warehousing and

postal

$\square$ finance

- sports, culture and entertainment

Figure 8: CI implementation according to industrial sector involved in questionnaire survey

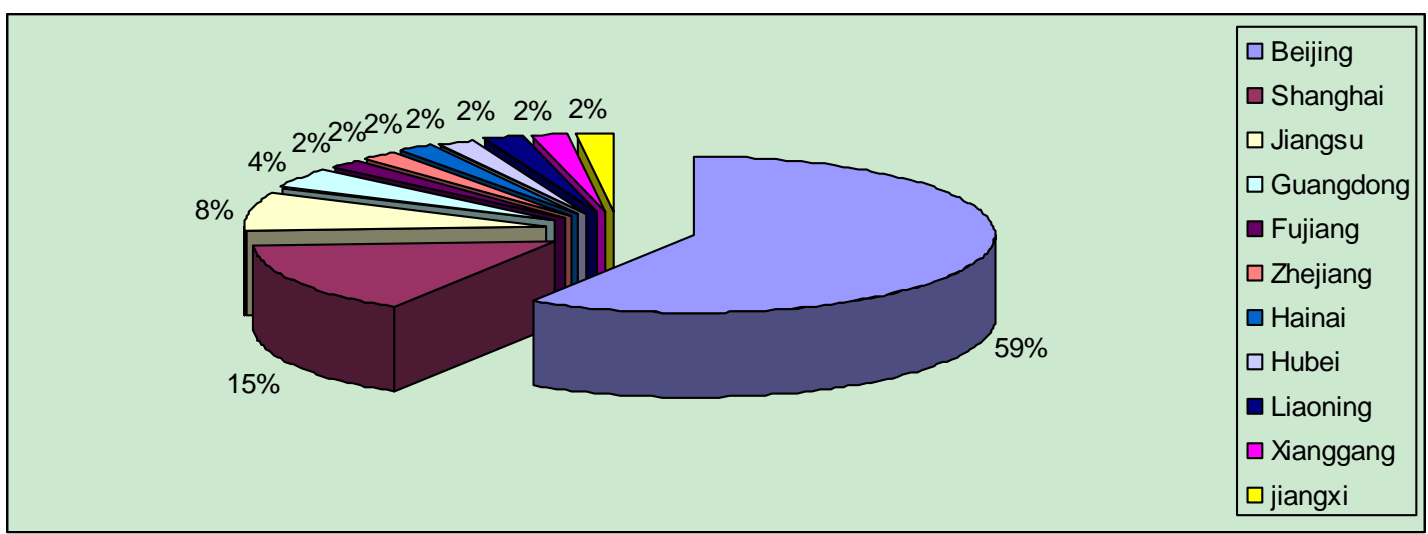

Figure 9: CI implementation according regional distribution

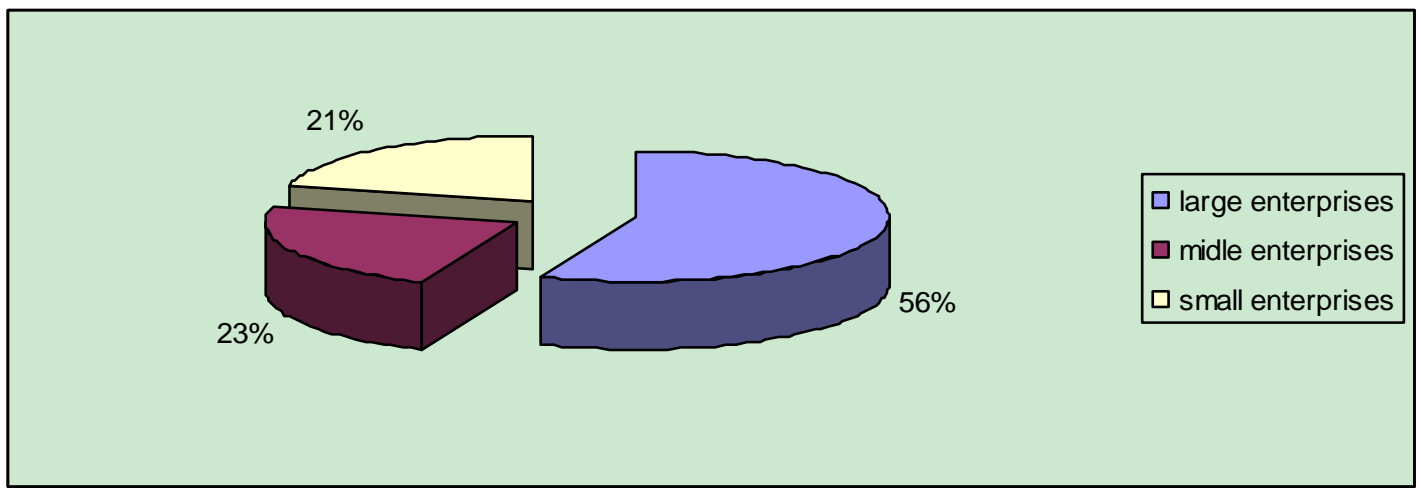

\section{Figure 10: CI implementation according to company size}

Respondents were mostly mangers or CI staff in the companies. In order to grasp the basic situation of CI in their companies and to make sure that the respondents completely understood what CI is (what was measured), we explained the subject before they answered our questionnaire. We also made a survey about the degree of attention these companies pay to CI by asking the respondents:

According to your own experience, do you think CI is indispensable before you make important decisions? (You can pick answer "strongly agree", "agree", "less agree", "disagree" or "strongly disagree"). 


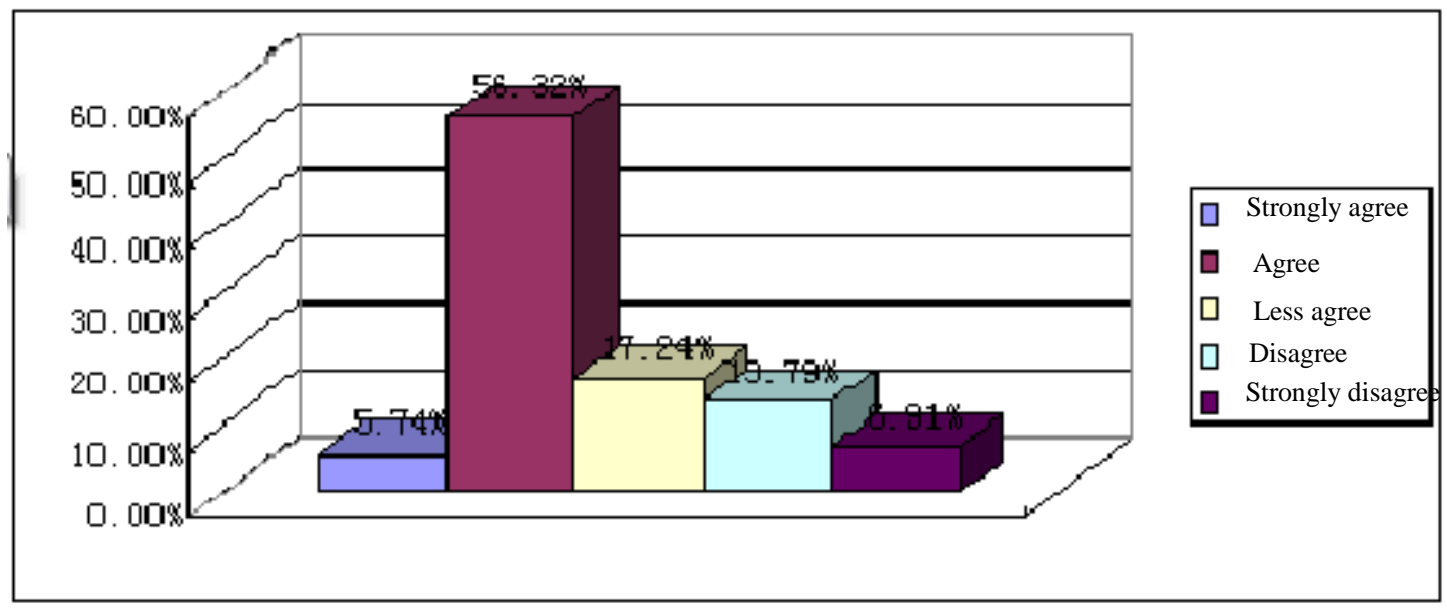

Figure 11: Chinese enterprises' attitude towards CI

The results are seen in Figure 11. In China many companies thought $\mathrm{CI}$ was equal to market investigation. For that reason CI was often undertaken by the market or sales department in their company (Xie et al., 2001). From figure 8 we find that the awareness of CI has improved and the percent that thinks $\mathrm{CI}$ is
4. having formal CI department and network;

5. CI institutionalized.

According to the survey we found that more than half of the Chinese companies dealt with CI. The sum of the levels of [1], [2] and [3]

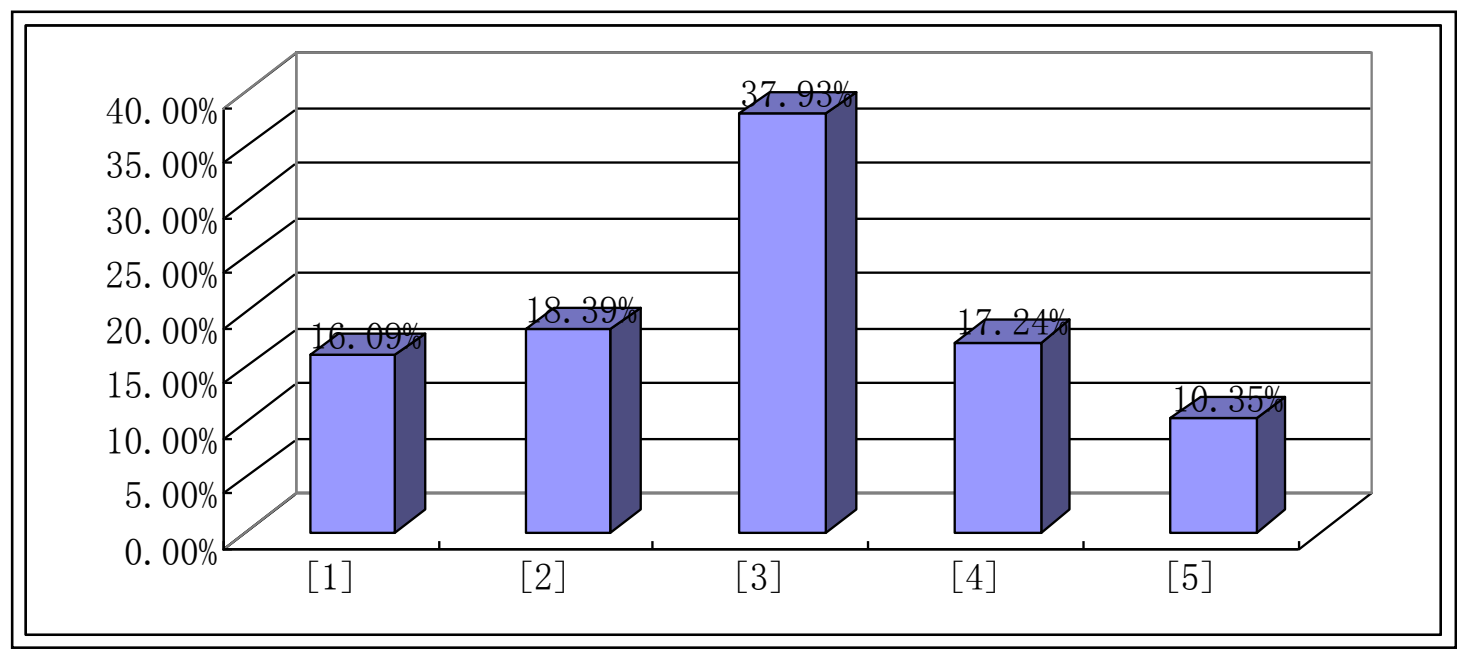

Figure 12: CI development level in Chinese enterprises in 2009

indispensable for decision-making account for more than half of those surveyed (strongly agree is $5.74 \%$, agree $56.22 \%$ ).

On the basis of previous divisions of CI involvement, we divided the development level of CI into:

1. no CI work at all;

2. having CI work, but no CI department;

3. formal CI department and network being planned; accounted

for

$65.52 \%$

$(10.95 \%+17.24 \%+37.93 \%)$, but most companies are in the position of forming or about to form formal CI functions ([3] accounted for $17.93 \%$ ). Comparing this with the survey from 1999 we see that the level of CI practice in China has made significant progress. But overall the level of CI practice in China is still not very high and it has still not matured. $16.09 \%$ of Chinese companies were completely unfamiliar with the CI function. 


\section{The CI market}

In China the CI market is composed of three aspects: CI consulting, CI training and CI software. There is no absolute boundary between the above CI markets. Many CI companies engage in two or three of these businesses. As an emerging market, the CI market is not in any way mature. According to our comprehensive study on the topic, we divided growth into three periods: sprouting period, growth period and bottleneck period (figure 13).

\subsection{The sprouting period (1994-2001)}

In the late 1970s and early 1980s information consulting appeared in China and in the early 1990s reached a relatively large development level. By the end of 1991 information consulting organizations reached 236. Some of them provide consulting services for enterprise strategy. In China CI services were originally undertaken by Information Institutes, universities, CI societies and the local government. With the CI need in enterprises increasing companies such as information consulting suppliers and information technology providers became aware of the business opportunity.

In 1992 the Shanghai Institute of Science and Technology Information organized a CI seminar for the first time. CI training in China then took the first step. In 1996 Beijing Normal University began to provide "CI further education" for enterprise staffs. Several CI consulting companies such as WanFang Co. Ltd., Beijing Competitive Intelligence Center, Beijing Huamen Co. Ltd. and Beijing Huanxin Co. Ltd. appeared. In the same period CI websites such as China.com and Humen.com appeared. In 1999 and 2001 Beijing Huanxin Co. Ltd. and Menglong Co. Ltd. developed CI software, but didn't strongly promote it. For that reason there was little social response. There were some CI providers in the Chinese market, but their number could be counted on one hand.

\subsection{The growth period (2002-2007)}

In 2001 China joined WTO, and the Chinese market was further opened to the outside world. This made the outside competitive environment that Chinese companies faced more complex and CI demand increased. In addition scholars, information institutes, universities and local governments made efforts to introduce CI to enterprises.

In 2003 CI professional qualification such as "Information Analyst" and "Competitive Intelligence Analyst" appeared in China. This marked the arrival of the era of CI professionalization in China. In 2004 SCIC established the "China Competitive Intelligence Consultation and Training Center" and began to give CI training as an independent training program. The number of people to take part in CI training reached about 3000 in China each year during that period. The number of companies and organizations to engage in CI services reached about 1000 (Mingjin Xu, 2008).

During that time websites for CI training and communication were active. Some CI websites such as Sinoci.com.cn and Zoomchina.com were particularly popular.

A famous IT company in China, Baidu, entered into the CI software market in 2002. Following Baidu, more than 20 companies including UK Autonomy entered the Chinese CI market. In 2004 the sales of CI related software reached more than 30 million RMB, a more than $80 \%$ increase compared to 2003 (fan $\mathrm{Wu}, 2005)$.

The CI market was now in a flourishing period, but many companies especially CI software developers were more like copycats following Baidu. The boom of the CI market was due to

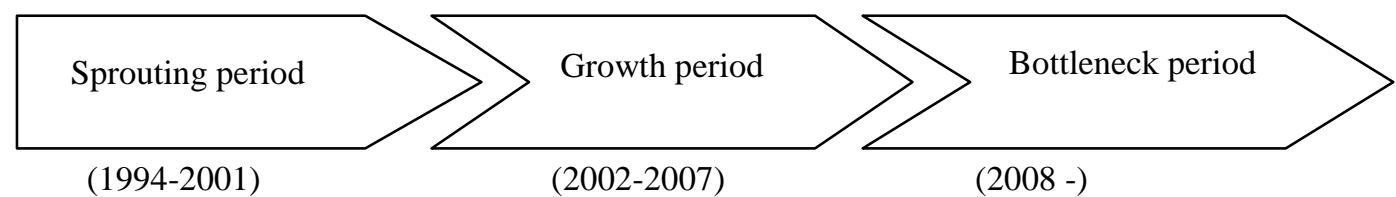

Figure 13: The growth of the CI market 
a leading effect, not to new product development. This indicated an instability in the development of the Chinese CI market and opened for its decline, in the period to come.

\subsection{Bottleneck period (2008 - )}

After a short-lived prosperity, in 2006 many CI software companies such as Baidu Co. Ltd. and Tianxiahulian Co. Ltd. dropped out of CI software market. In the meantime people began to cast doubt on CI performance. Chunfeng Wang (Chunfeng Wang, 2006) published online the article "Is Competitive Intelligence the emperor's new clothes?". These signals hinted to the instability of the CI market in China. In 2008 CI software developers moved to other industries, switched to other IT business sectors or went silent.

Following the decline in the CI software market, in 2009 the CI training market also began to decline and some CI training organizations disappeared.

Former CI websites such as Huanmen.com and Zoomchina.com were closed. But there were also new CI websites appearing such as chinacir.com.cn and zitview.com.

Linking the above survey on Chinese CI practice with the recent situation of the CI market in China, we have made an analysis about the reason for the coming bottleneck period. It's still unlikely that the Chinese CI market will be shrinking further when one considers today's CI demand. Instead the level of CI services in China today is now too limited to meet the demand. So it's crucial for Chinese CI companies to develop and update their products and services.

\section{CI education}

With SCIC founded in 1994, CI education in China appeared. In 1995 China Science and Technology University formally enrolled graduate students for a master's degree in CI. In 2000 China Institute of Science and Technology Information, National Defense Science and Technology Information Center and Peking University united to form a Ph.D. in CI. At present there are 23 universities engaged in CI professional education, and there is an elaborated system of college professionals offering $\mathrm{CI}$ education on the undergraduate, master and doctor level.

\section{Establishing CI laws and regulations and a professional ethics}

Since CI was born in China in the 1980s, professionals have advocating collecting intelligence through legal methods.

Due to the nature of competition, decisionmaking, value and secrecy, CI activities must be in compliance with the "rules of the game" in the market. In China there are some laws related to CI such as the Law of the Peoples Republic of China Against Unfair Competition, Unfair Competition Prevention, the Trade Secret Protection Act and Copyright Law of the Peoples Republic of China. These laws are restraining CI practices, but do not limit or regulate the $\mathrm{CI}$ industry as such. Many professionals think it is a pity that laws specialized for CI don't exist in China.

CI ethics in China is very slow area to develop and China does still not encourage any authoritative sets of CI ethics.

We think the basic reason for this is that in China CI still do not play an important role for the economic development and strategy support. The scale of CI practices is limited and still underdeveloped. The support and attention given to this area from the government is not sufficient. Government guidance is important for any task in a country such as China, with a strong collectivist tradition.

\section{Conclusions}

Generally speaking, all aspects of CI have entered a critical phase in China. We think the future of CI development will be connected to the following aspects:

\subsection{CI theory}

With further reforms in the market system in China, the competition that Chinese enterprises will be facing will increase. The business environment will become more complex and intense. In recent years China achieved great advances in technological innovation. This has improved the position for Chinese companies and the general economic and national development. With further development and professionalization of CI, CI management will become more important. At the same time this is also a weak link.

We think the future direction of CI academic research in China will be focused on the following five aspects: A CI that goes in the direction of more complex competition such as dynamic and cooperative competition, CIS, 
CTI, the research of integration with $\mathrm{KM}$ and $\mathrm{CI}$ and CI management.

\subsection{Methods and technologies for $\mathrm{CI}$}

Analytical methods and technologies used for CI is mainly introduced in China from abroad, and has been lacking in innovation. It seems method and technology is the weak point of CI research. Strengthening CI innovation in this aspect is key to developing CI as a science for academics around the world, maybe especially in China.

\subsection{CI practices}

According to our surveys, in 1999 and 2009 about CI practices in China, CI applications in Chinese enterprises is still performed at a medium level in the organization, gathering information and conducting market surveys. At the same time in figure 13 we saw that CI practices in China is gradually developing towards a higher level of sophistication.

\subsection{CI markets}

The CI market in China is facing a period of decline. The situation is not clearly optimistic. We think the basic reason is that the value of CI has not been developed in depth. As a consequence people don't know enough about $\mathrm{CI}$ and even doubt its value. The other basic reason is that the CI functions have in a way hidden other areas of interest such as information systems, knowledge management system, decision support system and business intelligence system. The CI role is often performed by employees without a clear CI tag, such as salesmen, R\&D personnel, even managers. This has created much confusion as to what CI really is. From this perspective it would be better if a new and broader term could be found that reflected the values of all of these activities.

\subsection{Cultivation of CI talent}

It is difficult to see how someone can be an expert on CI without having in-depth knowledge of other areas. Future development of CI talent mentioned above is therefore inseparable from the cultivation of interdisciplinary talent.

\subsection{CI laws and CI work ethics}

Due to the underdevelopment of CI practices and the CI market, the construction of CI laws and the forming of a CI work ethics will be a longer process than could otherwise have been expected.

\section{Reference}

Changhuo, B., Gang Z., Yan L., Ying H. 2005. Competitive Intelligence Grow Up ReviewWritten for the $10^{\text {th }}$ Anniversary of SCIC. Journal of the China society for Scientific and Technical Information, 24(1): 3-19.

Qihao L. 2008. The Origin of Competitive intelligence. Competitive Intelligence, Winter issue.

Changhuo B., Yan L., Xiuling W. 2006. Human Intelligence Network. Information Studies: Theory \& Application, 29(2): 129141.

Changhuo, B., Ying, H. and Gang, Z. 2004. Research on Developing Competitive Intelligence System. New Technology of Library and Information Service (1): 76-80.

Chuangye, Y. 2005. The Research of Human Intelligence Network in Competitive Intelligence. Peking: Peking University.

Xiangyu T., Songzhen L., Liren G. 1995. The Thought of Establishment of China's Quick Response System of Competitive Intelligence. Information Science and Technology (4): 34-38.

Zhao S., Yufeng Z. Analysis of a Model of CI Computer System. 2011. Journal of the China Society for Scientific and Technical Information 20(1): 39-45.

Keqiang, Y. 2003. Analysis and Design of Competitive Intelligence Software. Peking: Peking University.

Li L. 2007. The Integration of Competitive Intelligence and Knowledge Management. Chongqing: Southwestern University.

Junping Q., Yang Z., Rui Z. 2005. On Competitive Intelligence System and Knowledge Management System. Library and Information Service (9): 31-35.

Tiehui Q., Wenfang S., Chuangye Y. 2003. On the Relationship Between Competitive Intelligence and Knowledge Management Library and Information Service (11): 2832.

Yuefen W., Peng S., Xinhao W., Changhuo B. 2006. Application of Knowledge map in Intelligence Analysis. Library and Information Service, 50(12): 83-87.

Wei F., Bo S. 2008. Analysis of the Research on Competitive Intelligence and Knowledge Management. Journal of Information (10): 72-74.

Xiujuan L., Yawei Y. 2009. Review of Research on National Competitive Intelligence. Information and Documentation Services (6): 18-21. 
Yan L., Xinli Z., Zhongying Q. 2006. Analysis of the Status of Competitive Technical Intelligence. Journal of the China Society for Scientific and Technical Information 25(2): 242-253.

Jin C., FangZhen Y. 2006. A Research on SPRE Technological Innovational Audit Model and Its Application. Research \& Development Mangement 18(5): 9-14.

Ping L., Jing Z., Changwen Q. 2005. Facture of Patent Technology Maps and Its Demonstration: Citing Laser Information Storage Technology As an Example. Chinese Journal of Management, 2(5): 555-558.

Xianneng K. 2008, The Construction of the Analysis Method Frame of Competitive Technology Intelligence Based on Innovation Process. Beijing: Graduate University of Chinese Academy of Sciences.

Qihao, L and Zuozhi, Z. 1989. Anatomy of JETRO's Overseas Technological Intelligence Activities. Journal of the China Society for Scientific and Technical Information 1989, 8(4): 81-83.

Gang Z. 2004. Establishing National CI System: Object and Principle. Journal of the China Society for Scientific and Technical Information, 23(3): 367-371.

Gang Z. 2004. China need Build the National Competitive Intelligence System. Digest of Management Science (2): 6-8.

Xiang T. 2008, National Competitive Intelligence: What It Is, Why and How to do it?, Shanghai: Shanghai Scientific \& Technical Press.

Solberg Søilen, K. 2005. Introduction to public and private intelligence. Lund: Studentliteratur.

Yanning Z., Feng C., Xiaoyuan Z. 2009. Findings from a Site Investigation into the Program of Promoting Competitive Intelligence Application to Enterpriese of Hunan Province of China. Journal of the China Society for Scientific and Technical Information, 28(1): 155-160.

Xinzhou, X., Na, L. and Shaoqi, H. 2011. Investigation and Analysis of The Enterprise Informatization and Competitive Intelligence of China ( I ). Journal of the China society for scientific and technical information, 20(3): 295-302.

Xinzhou, X., Na, L. and Shaoqi, H. 2001. Investigation and Analysis of The Enterprise Informatization and Competitive Intelligence of China (II). Journal of the China society for scientific and technical information, 20(4): 435-442.
Zuozhi, Z. 2007. The Memorabilia of Competitive Intelligence in China from 2000 to 2005. Available online at URL: http://www.istis.sh.cn.

Mingjin Xu. 2008. Research on the Operating Actuality, Problem and Countermeasure of the Chinese Enterprise Competitive Intelligence Intelligence Work. Library and Information (5): 86-90.

Fan Wu. 2005. Competitive Intelligence in not a "Chicken Ribs". Software World (1): 4647. 